Research Article

\title{
Activation of Motor Fuels
}

\author{
Vorobiev Yu $\mathrm{V}^{1}$, Baronin $\mathrm{GC}^{1}$ and Dunaev $\mathrm{AV}^{2 *}$ \\ ${ }^{1}$ Tambov State Technical University, Russia \\ ${ }^{2}$ Federal State Budgetary Scientific Institution, Russia
}

*Corresponding author: Dunaev AV, Federal Scientific Engineering Centre, Doctor of Technical Sciences, Leading Research, Russia.

Received Date: January 17, 2019

Published Date: February 08, 2019

\begin{abstract}
The device described activator of motor fuels by the patent RF No. 2411074, which is facilitated by the fractional composition of gasoline, aviation and diesels fuel, rapeseed oil, as well as modification of them hydrocarbon molecules-family in the fuel. The prospects of application of the activator.

Activator tested three bench motor in Russia, environmental testing of exhaust emissions of engines in Rochester Institute (USA), control hematological indicators of eight grades of gasoline and three grades of diesel fuel, tens of chromatogram fuels before and after activation, control freezing point and smoke of diesel engines. Activator generates a unique water-fuel emulsion.

Chromatograms of activated diesel and gasoline fuels showed a decrease in the proportion of heavy hydrocarbons and the formation of light molecules: hexane, heptane, 3 metal-pentane to $37 \%$, reducing the sulphur content from 0.032 to $0.015 \%$, resins from 7.4 to $0.8 \mathrm{mg} / 100 \mathrm{ml}$. In gasoline, the content of octane-determining toluene increased to $16 \%$, in jet fuel nonane and decan to $21 \%$. Successful activation of biofuels.

Chromatographs research, bench and operational tests confirmed the irreversibility of the modification and the continuation of it after the release of fuels from the activator.

Activation helps reduce the consumption of fuels by $20-27 \%$ without reduction capacity of engine, decreasing the opacity of exhaust gases of diesel engines, toxic-ness of petrol engines, the reduced freezing point of diesel fuel, it should be cleaned of tars and sulphur compounds.

Stable, effective and versatile action on fuel was introduced in the activator according to the patent of Russian Federation No. 2411074. Its non-reversibility of fuels suitable for automotive, transport, aviation and liquid-propellant engines. Achieved activation is useful in the production of fuels that meet the requirements of EURO-3 and EURO-4. Activation of different petroleum products are brought to close indicators, with the selection of sulphur, with the destruction of resinous compounds, with decreasing temperature of freezing.
\end{abstract}

Keywords: Activator; Mechanochemistry fuel consumption; Freezing point; Sulphur; Smoke diesels; Activation mechanism; The opposite effect of electrons

\section{Introduction}

Improvement of engines in the motor industry and improve their service is very important, increases their reliability, resource, reduces fuel consumption, the harm of exhaust gases. It is solved mainly by high-tech and expensive modernization of their fuel systems.

However, the improvement of fuel efficiency and environmental friendliness of engines can be solved more easily - the modification of fuels. For this purpose, test magnetic and electromagnetic [1], cavitation Vorobyov $\mathrm{Yu}$, et al. [1,2-5], tribiotechnical processing, homogenization of fuels [1], the introduction of additives. But outside the magnetic field changes reversibly fuels, limiting such activation.

At the same time, in 1887, Mechanochemistry was revealed as a class of changes in substances under the influence of mechanical forces [1,6,7]. By 1960, the Mechanochemistry of motor oils was generalized [6]. In General, it is shown that even where there are strong bonds, their rupture by mechanical stresses above the strength limit of atomic bonds is possible [6]. 
A consequence of Mechanochemistry, for example, in heptane is the rupture of chains with energy yield of $\sim 419 \mathrm{~kJ} / \mathrm{mol}$ Akhmatov AS [6], the appearance of free valences, radicals, for example, R-CH2 - with high reactivity, although the changes can be reversible.

Mechanical activation is characterized by simplicity, low power consumption [8]. Production of motor fuels and oils from oil requires high energy costs in large-scale installations, and mechanical activation increases the depth of processing in simple equipment. Research in Mechanochemistry continues [1,6-10].

Mechanochemistry destroys oil fractions with the formation of low-molecular homologues, forms stable products, such as methane, hydrogen, $\mathrm{C}$, destruction of resins, sulfur compounds and sulfur deposition.

The mechanism of destruction of saturated hydrocarbons is the rupture of chains, and unsaturated ones are destroyed through the formation of saturated bonds. It is possible to hydrogenate their products of destruction of the initial substance [8]. A distinctive feature of the Mechanochemistry of hydrocarbons continues outside the equipment.

A significant breakthrough in the activation of fuels was the creation of an activator (RF patent No. 2411074), thanks to which the engines achieved savings of up to $31.9 \%$ of gasoline [2,3]. This is confirmed in [1], where step by step, the electro-magnetic activation of gasoline increased its calorific value by $28 \%$ ! But the implementation of the breakthrough was hampered by the lack of a clear activation mechanism.

\section{Object of Research}

The object of research - the mixer-activator according to the patent of Russian Federation No. 2411074 [2,3]. The activator (Figure 1) in a cylinder $150 \mathrm{~mm}$ long, 30-50 $\mathrm{mm}$ in diameter has three chambers, is integrated into any fuel system of engines, does not require a drive, chemicals, does not reduce the life of engines.

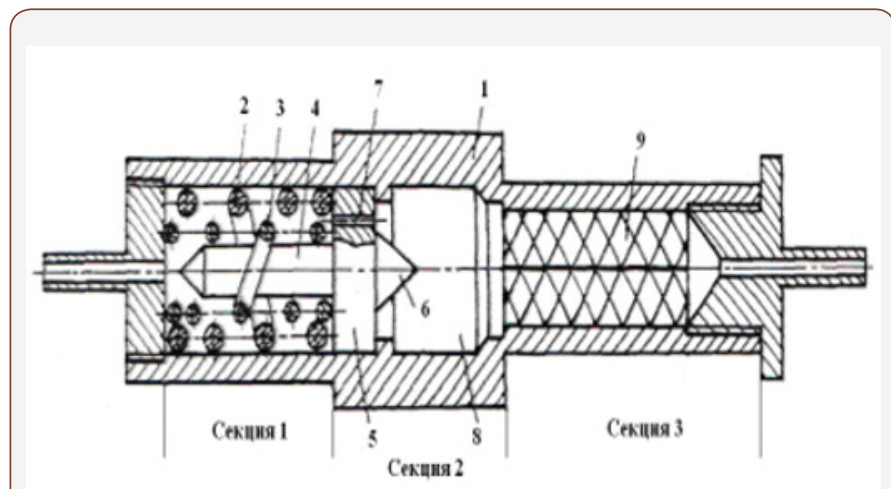

Figure 1: Scheme of the combined strength of the static mixeractivator according to the patent of Russian Federation No. 2411074: 1 - body; 2 and 3 - twisted elements; 4 - rod; 5 - disc microchannels; 6 - cone of the rod; 7 - channel; 8 - intermediate chamber; 9 - mixer of the crossbars.

In the first chamber of the activator takes place a counter-helical stirring, abrasion jets, the fragmentation of the clusters. Through the capillaries, the jets are injected into the second chamber and their cavitation is crushed. In the third chamber, the fragments of molecules are pressed through the micro foils, which continues their rupture. This ensures the irreversibility of fuel conversion - a special advantage of the activator, its uniqueness.

\section{Methods and Results of Tests of the Activator}

The activator has been repeatedly checked by chromatography of various fuels, control of their consumption Vorobyov $\mathrm{Yu} \mathrm{V}$, et al. $[2,3]$, emission of harmful gases of automotive engines, lowtemperature properties. Chromatograms of activated diesel fuel and gasoline showed a decrease in heavy hydrocarbons and the formation of lungs: hexane, geptan, 3-methyl pentane to $37 \%$, a decrease in sulfur content from 0.032 to $0.015 \%$, resins from 7.4 to $0.8 \mathrm{mg} / 100 \mathrm{ml}$. In gasoline, the content of octane-determining toluene in-creased to $16 \%$, in aviation kerosene nonan and decan to $21 \%$ [2]. Successful activation of biofuels.

\section{Such studies with the activator were carried out}

- $\quad$ Bench tests of the KamAZ-740 and ZMZ-406 engine in July 2011 at the Military Aviation Engineering University.

- $\quad$ At the research Institute VNIITiN in 2013 for the complex of methods of accelerated testing of petroleum products, as well as on engines, single-cylinder installations, using the methods of dam monitoring specified in the reference document on petrochemicals. The activated avtobenzines Normal-80, Regular-92, Premium-95, Super-98 according to GOST R 51106-97, gasoline AI-92 according to TU 38.001165-97, AI98 according to TU 38.401-58-127-95. Were tested gasoline «Superlux» and «Premium» company «Beyond Retroleum», as well as diesel fuel grades B and C, type II, fuel class 1 type I according to GOST R 52368-2005 (EN 590:2009, diesel fuel Euro).

- $\quad$ The improved activator was tested on diesel YaMZ-236 with three different fuels for installations in the line to the injection pump and on the discharge from it [3].

- The activator was tested in Rochester Institute of Technology (USA), where the decrease in sulfur content in fuels up to $50 \%$, resins 7-9 times, emissions in the exhaust gases: NO - up to $17 \%$, NO2 - up to $14 \%$, and CO - up to $49 \%$.

-In 2009-2016, a dozen activators were tested on gasoline and diesel cars with a reduction in gasoline consumption to $31.9 \%$ !

\section{Research and Test Results}

\section{Studies and tests have shown}

a. reduction of diesel fuel consumption with the first activator samples by 26.5 and $28.6 \%$, and gasoline by 21.3 , 27.7 and $31.9 \%$,

b. decreases the hydrocarbon content with the number of carbon atoms more than 10 , with the synthesis of light hydrocarbons (hexane, heptane, 3 n-pentane) to 20-30\%,

c. sulfur content in fuels is reduced by 1.5-2 times, and resins by 9 times, the content of toxic gases is reduced by $\mathrm{CO}$ to $79 \%$, by NO, NO2 to $14 \%$. 
The results of tests of the improved idling activator of the diesel engine YaMZ-236 (Table 1) showed a decrease in fuel consumption by $26.3 \%$.

Table 1: Test results of the improved activator.

\begin{tabular}{|c|c|c|c|}
\hline $\begin{array}{c}\text { Frequency } \\
\text { Rotation, } \text { min }^{-1}\end{array}$ & $\begin{array}{c}\text { Activator } \\
\text { Consumption }\end{array}$ & $\begin{array}{c}\text { Fuel } \\
\text { Consumption } \\
\text { for 5 Minutes } \\
\text { of Testing, } \mathbf{c m}^{3}\end{array}$ & $\begin{array}{c}\text { Savings, } \\
\mathbf{c m}^{3} / \%\end{array}$ \\
\hline 1100 & + & 267 & $71 / 21,0$ \\
\hline 1100 & + & 253 & $85 / 25,2$ \\
\hline 1100 & - & 338 & - \\
\hline 1100 & + & 267 & $71 / 21,0$ \\
\hline $1280 \ldots 1300$ & + & $244 ; 209,7$ at & 1100 min $^{-1}$ \\
\hline Medium & & 249,18 & $88,3 / 38,0$ \\
\hline
\end{tabular}

Figure 2 shows an extraordinary modification of LUK Oil diesel fuel. The graphs show the red lines of the initial fraction of the number of carbon atoms, and the blue lines -the fraction after the activation of fuels.

\section{Analysis of research results}

What are the reasons for the significant [3] increase of fuel calorific value by the activator? Note, that for burning the fuel must be dispersed to molecules, which seems to be facilitated in the activator. Further, when warming up, molecules must undergo fragmentation, the separation of hydrogen atoms, a complete gap between the carbon atoms. In parallel, the dissociation of oxygen molecules should go. Only after that the atoms of the fuel combine with atoms of oxygen. And if the dissociation of molecules of fuel and oxygen is carried out in advance, the heat of combustion will not be spent on the preparation of fuel and its calorific value will be greater than in the calorimetric bomb. This may be one of the reasons for the increase in calorific value (Table 2), which is confirmed by the increased, in comparison with liquid oil products, calorific value of oil gases, as if dispersed hydrocarbons, where there is no need to break the bonds between the carbon atoms.
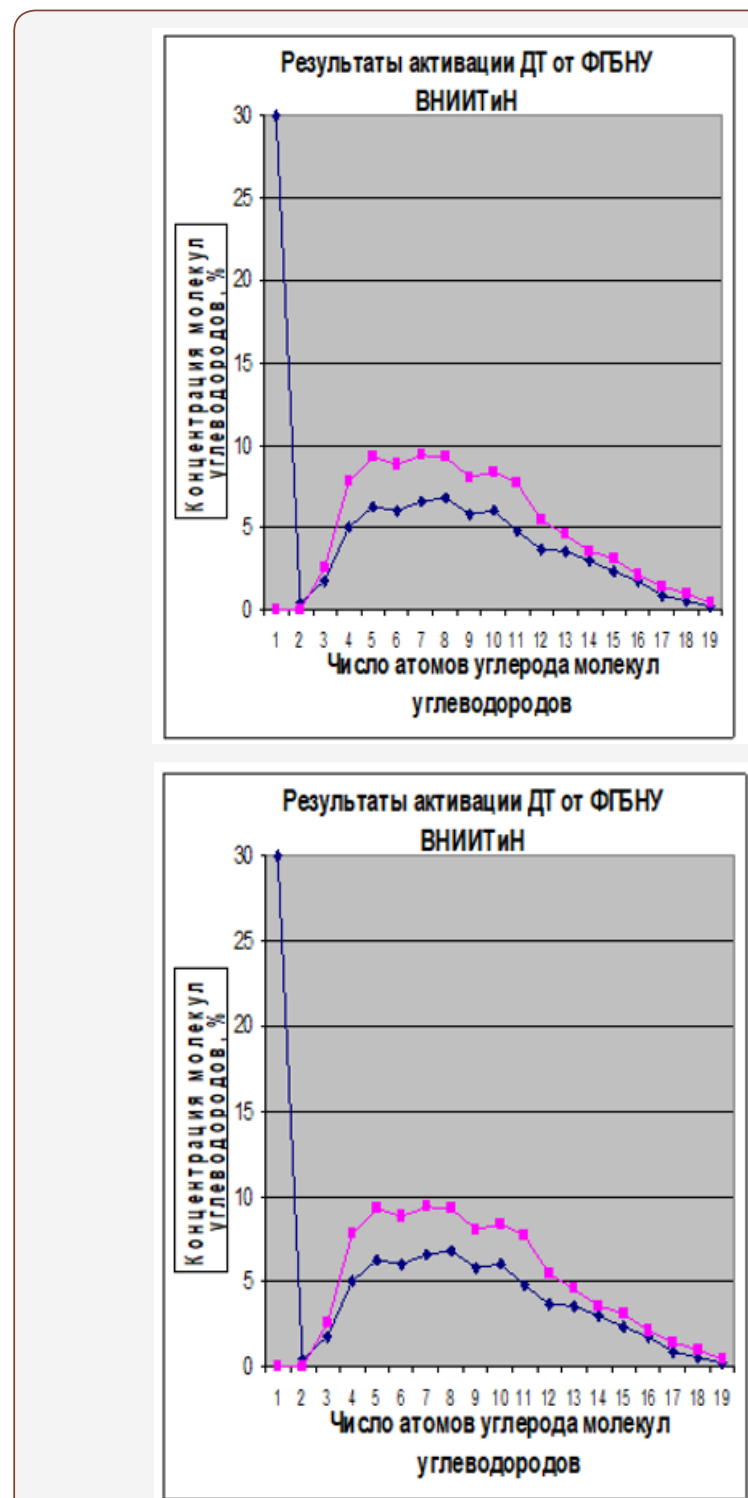

Figure 2: Modification of diesel fuels: a) - the company "LUKOil", b) from UNIITIN by the chromatograph Crystallux-4000M in accredited forensic laboratories: less heavy, the new light faction.

Table 2: Conversion of hydrocarbon molecules under the influence of electro-magnetic and tribochemical effects according [12].

\begin{tabular}{|c|c|c|c|c|c|c|}
\hline \multirow{2}{*}{\multicolumn{2}{|c|}{$\begin{array}{l}\text { Initial Fraction; Heat of Com- } \\
\text { bustion, } Q, \mathrm{~kJ} / \mathrm{mol}\end{array}$}} & \multicolumn{2}{|c|}{$\begin{array}{l}\text { Composition of } \\
\text { Fractions }\end{array}$} & \multirow[t]{2}{*}{ The Ultimate Faction } & \multirow{2}{*}{$\begin{array}{l}\text { Heat of Combustion of Converted } \\
\text { fuel, } Q, \mathrm{~kJ} / \mathrm{mol}\end{array}$} & \multirow[t]{2}{*}{ Positive Effect, \% } \\
\hline & & $1^{\text {st }}$ Phase & $2^{\text {nd }}$ Phase & & & \\
\hline \multirow{2}{*}{$\mathrm{C}_{8} \mathrm{H}_{18}$} & \multirow{2}{*}{$Q=5470$} & $\mathrm{C}_{4} \mathrm{H}_{8}$ & $2 \mathrm{C}_{2} \mathrm{H}_{4}$ & $2 \mathrm{C}_{2} \mathrm{H}_{4}$ & \multirow{2}{*}{$Q=5607$} & \multirow{2}{*}{2,5} \\
\hline & & $\mathrm{C}_{4} \mathrm{H}_{10}$ & $\rightarrow$ & $\mathrm{C}_{4} \mathrm{H}_{10}$ & & \\
\hline \multirow{3}{*}{$\mathrm{C}_{8} \mathrm{H}_{18}$} & \multirow{3}{*}{$Q=5470$} & $\mathrm{C}_{2} \mathrm{H}_{2}$ & $\rightarrow$ & $\mathrm{C}_{2} \mathrm{H}_{2}$ & \multirow{3}{*}{$Q=5900$} & \multirow{3}{*}{7,86} \\
\hline & & $2 \mathrm{C}_{2} \mathrm{H}_{4}$ & $\rightarrow$ & $2 \mathrm{C}_{2} \mathrm{H}_{4}$ & & \\
\hline & & $2 \mathrm{CH}_{4}$ & $\rightarrow$ & $2 \mathrm{CH}_{4}$ & & \\
\hline \multirow{3}{*}{$\mathrm{C}_{8} \mathrm{H}_{18}$} & \multirow{3}{*}{$Q=5470$} & $\mathrm{CH}$ & $0,5 \mathrm{C}_{2} \mathrm{H}_{4}$ & $0,5 \mathrm{C}_{2} \mathrm{H}_{4}$ & \multirow{3}{*}{$Q=5975$} & \multirow{3}{*}{9,23} \\
\hline & & $\mathrm{C}_{5} \mathrm{H}_{6}$ & $2 \mathrm{C}_{2} \mathrm{H}_{4}$ & $2 \mathrm{C}_{2} \mathrm{H}_{4}$ & & \\
\hline & & $3 \mathrm{CH}_{4}$ & $\rightarrow$ & $3 \mathrm{CH}_{4}$ & & \\
\hline \multirow{4}{*}{\multicolumn{2}{|c|}{$Q=5470$}} & $2 \mathrm{C}_{2} \mathrm{H} 2$ & $2 \mathrm{C}_{2} \mathrm{H}_{2}$ & $2 \mathrm{C}_{2} \mathrm{H}_{2}$ & \multirow{4}{*}{$Q=7001$} & \multirow{4}{*}{28} \\
\hline & & \multirow{2}{*}{$0,5 \mathrm{C}_{2} \mathrm{H}_{4}$} & $0,5 \mathrm{C}_{2} \mathrm{H}_{3}$ & $0,5 \mathrm{C}_{2} \mathrm{H}_{3}$ & & \\
\hline & & & $0.5 \mathrm{H}$ & $0.5 \mathrm{H}$ & & \\
\hline & & $3 \mathrm{CH}_{4}$ & $3 \mathrm{CH}_{3}$ & $3 \mathrm{CH}_{3}$ & & \\
\hline
\end{tabular}


(Table 2) Conversion of hydrocarbon molecules under the influence of electro-magnetic and tribochemical effects according [1].

Thus, it can be assumed that the rupture of bonds in hydrocarbons with the formation of short - and long-lived radicals [11] reduces the cost of combustion heat for splitting molecules into atoms. And the longer the hydrocarbon chain is, the more significant the release of the energy of bonds in the chains can be (Table 3). And prof. Kanarev FM [15] emphasized that the more acts of mechano-chemistry influence on the substance, the deeper its modification. Table 3 shows that with the elongation of the molecules, the energy costs for the bonds of carbon atoms grow significantly, and by mechano-chemistry it can be isolated.

Table 3: Energy bonds between the carbon atoms in hydrocarbon molecules.

\begin{tabular}{|c|c|c|c|c|}
\hline \multirow{2}{*}{ No } & \multirow{2}{*}{ Substance } & \multicolumn{2}{|c|}{ Heat of Combustion } & \multicolumn{2}{c|}{$\begin{array}{c}\text { Energy of the } \\
\text { Destructible Bond of } \\
\text { Carbon Atoms, kJ/mol }\end{array}$} \\
\cline { 3 - 4 } & & $\mathbf{k J} / \mathbf{m o l}$ & $\mathbf{k J / g}$ & - \\
\hline 1 & Graphite & 393,680 & 394,1 & - \\
\hline 2 & Hydrogen & 286,020 & 123,01 & - \\
\hline 3 & Methane & 890,930 & 55,73 & 220,98 \\
\hline 4 & Ethane & 1560,88 & 51,92 & 441,96 \\
\hline 5 & Propane & 2220,30 & 50,37 & 662,94 \\
\hline 6 & Bhutan & 2880,26 & 49,61 & 883,72 \\
\hline 7 & Pentane & 3511,50 & 48,73 & 1104,9 \\
\hline 8 & Hexane & 4165,82 & 48,40 & 1325,88 \\
\hline 9 & Heptane & 4820,39 & 48,19 & 1546,86 \\
\hline 10 & Octane & 5474,41 & 47,97 & 1988,82 \\
\hline 11 & Decan & 6783,16 & 47,72 & \\
\hline
\end{tabular}

Describes the features of the Mechanochemistry confirmed that modification of fuel continues beyond the activator according to the patent of Russian Federation No. 2411074. So, I have activated fuel source significantly increases in the mixture the proportion of activated:

a. in the in commercial fuel introduced $20 \%$ activated fuel (4.6\% of the light fractions) and after 15 min the mixture was formed $12 \%$ of light fractions,

b. similarly, if you enter $30 \%$ activated $(6,9 \%$ of light fractions) was created $39 \%$ of light fractions,

c. only $27 \%$ of light fractions were detected during the introduction of $40 \%$ activated ( $9.2 \%$ of light fractions),

d. and after entering $50 \%$ of the activated light fractions revealed even less.

The modification of the fuels behind the activator can also be explained by the action of free radicals [11]. But are all the mechanisms of increasing the heat of combustion of activated fuels identified? Here you can rely on the modern, the greatest physicist of all time, physical-chemistry Professor Kanarev FM [12]. It is shown that for the destruction of bonds between valence electrons of atoms it is enough to spend 2,56 eV of mechanical energy, and for the thermal break it is required twice as much - 5,13 eV. Since each isolated electron for its stability must obtain a thermal photon with an energy of 2,56 eV. But after mechanical separation of the valence electrons, instead of heat, absorb the ether photon total energy of $5.13 \mathrm{eV}$. Absorbing them, the valence electrons become active, join the pieces of broken molecules, emit photons of unnecessary essential and saturate the substance with energy of $5.13 \mathrm{eV}$ !

So, having spent the activator of $2.56 \mathrm{eV}$ of mechanical and chemicals that saturate the substance with energy of two thermal photons of $5.13 \mathrm{eV}$ or $248 \mathrm{~kJ} / \mathrm{mol}$ what can be the main reason for the increase of the calorific value of fuels (Table $2 \& 3$ ) and reduction of their consumption.

And if the connections are destroyed by resonant methods Popova NI, et al. [12], it will be possible to corner the modification of fuels, further increasing their calorific value. Confirmation of this is made in water electrolytic cells prof. Kanarev F.M. the heat transfers co-efficient value $29000 \%$ !!! [12].

However, on fuel combustion prof. Kanarev F. M. expressed another: «All effects associated with an increase in the combustion pressure of fuels in closed cavities are formed not by gases, but by photons» [12]. From here it is possible to propose a dual mechanism for increasing the calorific value of purchased fuel.

Activated diesel fuel also reduces the smoke of diesel engines. So, on bus NefAZ-5299-30-33 the smoke content was 3.5 m-1 (77.8 $\%)$, and with the activator $-2.7 \mathrm{~m}-1$ (68.7 \%). Low-temperature properties of diesel fuel L-0,05-62 GOST 305-82 tested in a climatic chamber KTV-0,08. It was revealed that commodity heating at a temperature of $-30{ }^{\circ} \mathrm{C}$ completely lost its fluidity, and the activated retained its at $-45^{\circ} \mathrm{C}$.

\section{Conclusion}

For the first time achieved a stable, efficient and versatile effect on motor fuels. Its irreversibility significantly reduces fuel consumption and can be used in their pro-duction according to EURO-4 standards.

\section{Acknowledgement}

None.

\section{Conflict of Interest}

No conflict of interest.

\section{References}

1. (2012-2013) Development of scientific bases of technology for alternative fuels for means of rail transport: report of the Railways reg No. 01201276764. M: mechanics and technolo-gy RAS scientific Centre.

2. Vorobyov Yu V (2013) Bases of the theory of mechanical activation of liquid media. Bulletin of Tambov state technical University. Tambov 19(3): 608-613.

3. Vorobyov Yu, Dunaev AV (2016) Improving the calorific value of the motor vehicle use fuels. Tractors and farm machinery, pp. 48-50.

4. Ganiev RF (2009) Development of scientific bases for the preparation of stable water-fuel emulsions and their efficient combustion in the boiler furnaces on the principles of nonlinear wave mechanics. Research report No. 02.516.11.6072 from 25.06.2007 (Ministry of education and science of the Russian Federation). Reports of the Academy of Sciences 427(2): 15-218.

5. Grumondz VT (2011) Treatment of hydrocarbon liquids in physical and chemical the physico-chemical phenomena in terms of bubble 
cavitation. Nizhny Novgorod, Bulletin University Lobachevsky's name 4(5): 2120-2122

6. Akhmatov AS (1963) Molecular physics of boundary friction. Pp. 472.

7. Butyagin P Yu (1971) The Kinetics and nature of mechanochemical reactions. Advances in chemistry 40: 1935-1937.

8. Dneprovsky KS (2003) Mechanochemical transformations of petroleum hydrocarbons: Abstract of dissertation. candidate of chemical Sciences: 02.00.13. Tomsk: Institute of chemical neftesintez, pp. 24

9. Dubinsky AM (1999) The Transformation of organic substances under the action of the mechacal stresses. Uspekhi khimii 68(8): 708-724.
10. Lyakhov NZ, Boldyrev VV (1982) The Kinetics of mechanochemical reactions. - News of the Siberian branch of the USSR Academy of Sciences, Ser. chem. sciences 5: 3-9.

11. Kanarev FM (2007) The Beginning of the physical chemistry of the microcosm. Eighth edition. Krasnodar: KubSAU, 753 p.

12. Popova NI, Skubnevskaya GI, Molin Yu N, Kotlyarevsky IL (1969) Synthesis and some properties of free radicals with triple bonds. Proceedings of the Academy of Sciences of the USSR. Ser chem 11: 24242430 . 